\title{
Linear endoscopic ultrasound examination of portal biliopathy
}

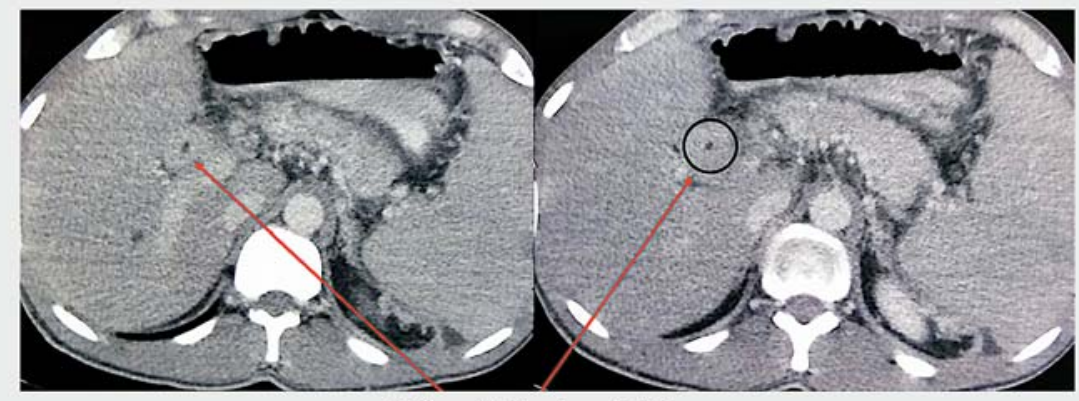

Diffuse thickening of CBD

- Fig. 1 Contrast-enhanced computed tomography showed diffuse thickening of the common bile duct (arrows, ring).

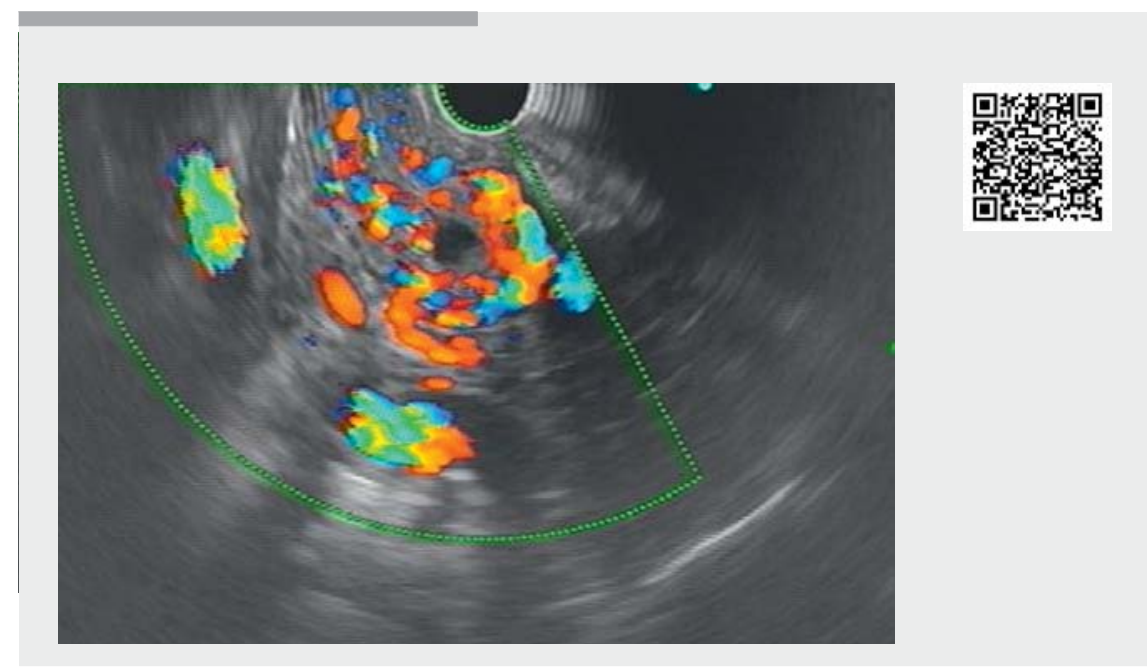

Video 1 Endoscopic ultrasound examination of portal biliopathy.

A 30-year-old man diagnosed 10 years ago with extrahepatic portal vein thrombosis underwent multiple sessions of endoscopic band ligation of esophageal varices. The last endoscopy session showed obliterated varices. Recently the patient complained of having had mild abdominal pain for 2 weeks. Laboratory evaluation showed mild anemia ( $\mathrm{Hb}$ $11 \mathrm{~g} / \mathrm{dL}$ ) and normal bilirubin (total $1 \mathrm{mg} / \mathrm{dl}$ ) with mildly elevated liver enzymes: alanine transaminase $68 \mathrm{U} / \mathrm{L}$, as- partate transaminase $42 \mathrm{U} / \mathrm{L}$, and alkaline phosphatase $168 \mathrm{U} / \mathrm{L}$ (normal<120U/L). Serum amylase and lipase were normal. Contrast-enhanced computed tomography showed diffuse thickening of the common bile duct (CBD) ( $\triangleright$ Fig. 1), multiple peripancreatic collaterals, and a normal pancreas. Magnetic resonance cholangiography could not be done because of the patient's claustrophobia. For CBD evaluation he underwent endoscopic ultrasonography (EUS) with a line-

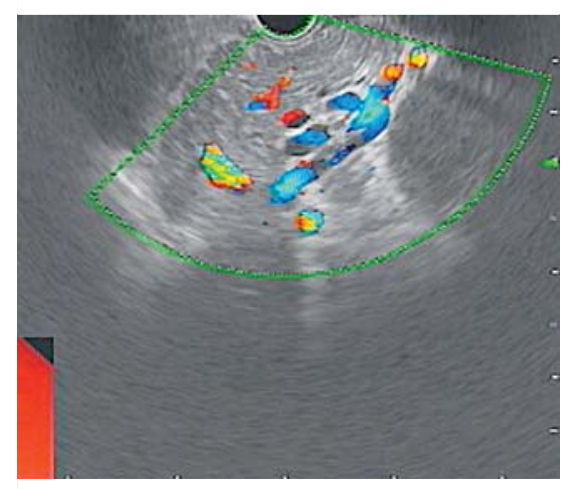

- Fig. 2 Endoscopic ultrasonography showing the pancreatic body with multiple peripancreatic collaterals.

ar echoendoscope. The EUS scope was passed into the duodenal bulb. From the duodenal bulb, multiple serpiginous linear structures were seen in the suprapancreatic region. On Doppler examination all these linear serpiginous structures showed a positive signal, and in the center a small, round, anechoic structure suggestive of the CBD was seen ( $\vee$ Video 1). The CBD was then traced from the ampulla to the hilum and back and forth. These paracholedochal collaterals resulted in a diffusely decreased caliber of the CBD. On CT examination these paracholedochal collaterals gave a pseudo-appearance of thickened walls of the CBD. Further EUS examination showed a normal pancreas, splenomegaly, and multiple peripancreatic and splenic hilar collaterals ( $\triangleright$ Fig. 2 ). The patient was managed symptomatically and asked to attend for regular follow-up. Portal biliopathy is defined as abnormalities in the extrahepatic bile duct with or without abnormalities in intrahepatic radicles in a patient with portal cavernoma [1]. The role of EUS is still evolving. EUS can accurately detect sites of varices in relation to the CBD (paracholedochal, intracholedochal, subepithelial, etc.), and that could be useful in patients undergoing endoscopic retrograde cholan- 
giography. EUS may be considered as an alternative diagnostic modality to magnetic resonance cholangiography when it is not possible to perform the latter.

Endoscopy_UCTN_Code_CCL_1AF_2AZ_3AD

\section{Competing interests}

None

The authors

Radhika Chavan, Zaheer Nabi, Sundeep Lakhtakia, Mohan Ramchandani, Jahangeer Basha, Rajesh Gupta, D. Nageshwar Reddy Department of Medical Gastroenterology, Asian Institute of Gastroenterology, Somajiguda, Hyderabad, India
Corresponding author

\section{Radhika Chavan, MD}

Asian Institute of Gastroenterology,

Somajiguda, Hyderabad - 500 082, India

drradhikachavan@gmail.com

\section{Reference}

[1] Dhiman RK, Saraswat VA, Valla DC et al. Portal cavernoma cholangiopathy: consensus statement of a working party of the Indian National Association for Study of the Liver. J Clin Exp Hepatol 2014; 4: S2-S14
DOI https://doi.org/10.1055/a-1028-6948

Published online: 7.11.2019

Endoscopy 2020; 52: E136-E137

(c) Georg Thieme Verlag KG

Stuttgart · New York

ISSN 0013-726X

\section{ENDOSCOPY E-VIDEOS}

https:|/eref.thieme.de/e-videos

回题 Endoscopy E-Videos is a free access online section, reporting 囬: on interesting cases and new techniques in gastroenterological endoscopy. All papers include a high quality video and all contributions are freely accessible online.

This section has its own submission website at

https://mc.manuscriptcentral.com/e-videos 